\title{
Sülfasalazine Bağlı Psikotik Özellikli Majör Depresif Bozukluk
}

\author{
Sulfasalazine-Induced Major Depressive Disorder With Psychotic \\ Features
}

\section{Ali KANDEĞER, M.D*. \\ Hazan TOMAR \\ BOZKURT, M.D**. \\ Güneş Devrim KICALI, \\ M.D***. \\ Prof. Dr. Özkan GÜLER, \\ M.D****. \\ *:Psikiyatri Bölümü, Isparta \\ Şehir Hastanesi, Isparta \\ **:Psikiyatri Anabilim Dalı, \\ Selçuk Üniversitesi, Konya \\ ***:Psikiyatri Bölümü, \\ Konya \\ Eğitim ve Araştırma \\ Hastanesi, Konya \\ ****:Psikiyatri Anabilim \\ Dalı, Selçuk Üniversitesi, \\ Konya}

Yazışma Adresi:

Ali KANDEĞER, M.D.

Psikiyatri Uzmanı, Isparta

Şehir Hastanesi, Isparta.

Isparta Şehir Hastanesi,

Merkez, Isparta, Türkiye.

Tel: +905374642212 Email:

dralikandeger@gmail.com
$\ddot{\mathbf{O} z}$

Ankilozan spondilit (AS); nedeni bilinmeyen, esasen omurgayı olmak üzere diğer eklemleri de etkileyebilen kronik inflamatuar bir hastalıktır. AS, spondiloartropatilerin prototipi olup dünya nüfusunun $\%$ 0,9'unu etkilemektedir. Sülfasalazin, AS tedavisinde kullanılan hastalı modifiye edici antiromatizmal ilaçlardan biridir. Sülfasalazinin; mani, depresyon ve psikoz gibi ciddi psikiyatrik problemler de dahil olmak üzere merkezi sinir sistemi üzerinde olumsuz etkilere yol açtığına dair olgular nadir olarak bildirilmiştir. $\mathrm{Bu}$ yazıda, psikotik özellikli majör depresif bozukluk nedeniyle başvuran bir erkek hasta sunulmaktadır. Hastada ciddi psikiyatrik belirtiler gelişirken, AS için günde $1000 \mathrm{mg}$ sülfasalazin alıyordu. Romatoloji bölümüne konsulte edilen hastanın, sülfasalazinin psikiyatrik semptomların nedeni olabileceğinden şüphelenildiği için, sulfasalazin tedavisi kesildi. Şikayetler, psikiyatrik tedavinin başlangıcından 1 ay sonra tamamen geriledi.

Anahtar Kelimeler: Ankilozan Spondilit, Depresyon, Psikoz, Sülfasalazin

\begin{abstract}
Ankylosing spondylitis (AS) is a chronic inflammatory disease of unknown cause and affects mainly the spine, but can also affect other joints. AS is the prototype of spondyloarthropathies that affects $0,9 \%$ of the world population. Sulfasalazine is a disease-modifying antirheumatic drug used in the treatment of AS. Sulfasalazine may cause central nervous system adverse effects such as serious psychiatric problems including mania, depression, and psychosis, and these symptoms have been reported to occur only infrequently. This present case reports a male patient who presented due to major depressive disorder with psychotic features. He had been receiving $1000 \mathrm{mg} /$ day sulfasalazine for AS while he developed serious psychiatric symptoms. The patient was stopped being given sulfasalazine after consulting rheumatology, as it was suspected sulfasalazine might have been the cause of his psychiatric symptoms.
\end{abstract}


Complaints were fully resolved 4 months after the beginning of the 1 year psychiatric treatment.

Keywords: Ankylosing spondylitis, Depression, Psychosis, Sulfasalazine

\section{Giriş}

Ankilozan spondilit (AS) nedeni bilinmeyen, esasen omurgayı etkilemekle birlikte diğer eklemleri de etkileyebilen kronik inflamatuar bir hastaliktır. AS spondiloartropatilerin prototipi olup Türkiye'nin yaklaşık \% 0,49'unu ve dünya nüfusunun $\% 0,9$ 'unu etkilemektedir (1). Non-steroid anti-inflamatuar ilaçlar, tercih edilen birincil tedavi yöntemidir. Sülfasalazin, AS tedavisinde kullanılan, hastalığ 1 modifiye edici antiromatizmal bir ilaçtır. Sülfasalazin, periferik eklem tutulumu olan AS hastaları için özellikle tercih edilmektedir (2). Sülfasalazinin antiromatizmal etkisinin tam mekanizması bilinmemekle birlikte, immünsupresif etki ve folik asit absorpsiyonunda bozulma nedeniyle ortaya çıktığı tahmin edilmektedir (3).

Sülfasalazinin; mani, depresyon ve psikoz gibi ciddi psikiyatrik bozukluklar de dahil olmak üzere merkezi sinir sistemi üzerinde olumsuz etkilere yol açtığına dair olgular nadir olarak bildirilmiştir. Bu yazıda, AS nedeniyle günde $1000 \mathrm{mg}$ sülfasalazin alırken psikotik özellikli majör depresif bozukluk nedeniyle başvuran bir erkek hasta sunulacaktır.

\section{Olgu Sunumu}

Hastamız, 46 yaşında erkek, evli ve iki çocuk babası, infaz koruma memuru olarak çalışıyor ve lise mezunu. Hasta psikiyatri polikliniğine mutsuzluk, uyku ve iștahda azalma, takip edildiği ve kötülük göreceği ile ilgili düşünceler ile başvurdu.

Yaklaşık 3 ay önce AS tanısı ile sülfasalazin tedavisi başlanıp dozu $1000 \mathrm{mg} /$ güne çıkartılmış ve sülfasalazin başlandıktan sonra halsizlik, moral bozukluğu, hiç bir şey yapmak istememe, uykularda azalma ve sik bölünme, iştahta azalma gibi belirtiler başlamış. $\mathrm{Bu}$ belirtiler 2 ay içerisinde giderek artmış, yaklaşık 7-8 kilo kaybetmiş, işe gitmek hatta aile üyeleri ile görüşmek istemiyormuş. Son ay içerisinde bu belirtilere ilaveten iş yerinde arkadaşlarının onu işten attırmaya çalıştığ dosyalarını değiștirerek ihbar edecekleri, her an polislerin gelip onu tutuklayacağı ile ilgili düşünceleri başlamış. Bu düşünceler nedeniyle evde telefonların dinlenebileceğini düşünüyor, s1k s1k pencereden polislerin gelip gelmediğini kontrol ediyormuş. Eşi ile yapılan görüşmede bu belirtileri daha önce hiç yaşamadiğ 1 , sülfasalazin tedavisine ek olarak steroid türevi ya da ek herhangi bir ilaç kullanmadığg öğrenildi.

Ruhsal durum muayenesinde genel görünümünde öz bakımı azalmış, öne eğik postürde idi. Bilinç açık, oryantasyon ve kooperasyon tamdı. Konuşması yavaşlamış, duygulanımı çökkündü. Düşünce içeriğinde anhedoni, referans ve perseküsyon sanrıları mevcuttu. Algı bozukluğu saptanmadi.

Hastanın öz geçmişinde herhangi psikiyatrik bozukluk, AS dışında sistemik hastalık saptanmadı. Ayrıca, soy geçmișinde psikiyatrik bozukluk öyküsü saptanmadi. Başvuruda yapilan hemogram, biyokimya, tiroid fonksiyon testleri ve B12 vitamin düzeylerini içeren hormon tetkikleri, elektroensefalografi ve beyin bilgisayarlı tomografisi normaldi.

Psikiyatrik semptomların ardından semptomların sulfasalizine bağlı olabileceği düşünülerek tedavide değişiklik olup olamayacağ $\breve{l}_{1}$ konusunda romatoloji bölümü ile konsultasyon gerçekleştirildi. Romatoloji bölümü tarafından sülfasalazin tedavisinin kesilmesi ve bir süre ilaçsız takip edilmesi önerildi. Sertralin $50 \mathrm{mg} /$ gün ve olanzapin 10 mg / gün reçete ederek ayaktan tedaviye başladık ve takip için 1 hafta içinde kliniğimize gelmesini istedik. Takip muayenesinde, reçete edilen ilaçları kullanmaya başladığını 
doğruladık. Hastanın 1 hafta içinde psikotik belirtileri kaybolmuş ve 1 ay içinde depresif belirtileri Beck Depresyon Envanteri puanlarına göre 41'den 9'a düşmüş ve \% 75-100 arasında azalmıştı.

\section{Tartışma}

Sülfasalazin, bir azo-bant ile 5-aminosalisilik asite (5-ASA) bağlı sülfapiridin'den oluşur (4). Sülfasalazinin etki mekanizması belli olmamasına rağmen, bazı çalışmalar folat metabolizmasını değiştirerek bu ilacın hücre aktivitesini etkilediğini bildirmiştir (5). 5-ASA ilacın anti-inflamatuar özelliklerini sağlar. Bir antiromatötik ajan olarak kullanıldığında bu ilaç için ölüm veya geç yan etki bildirilmemiştir. Olumsuz reaksiyonlar çoğunlukla ilk 2-3 ayda görülmesine rağmen, istenmeyen etkiler tedavi sirasinda herhangi bir zamanda ortaya çıkabilir (6). Olgumuzda psikiyatrik yan etkiler yaklaşık 2 ayda ortaya çıkmış ve sülfasalazin tedavisine başlandıktan 3 ay sonra şiddetli düzeye gelmiştir.

Özgeçmişte ve soygeçmişte psikiyatrik hastalık öyküsünün olmaması, sülfasalazinin kesilmesi psikiyatrik tedavinin başlanmasıyla hastanın ciddi belitilerinin 1 hafta içerisinde azalması hastanın yaşamış olduğu psikotik özellikli depresif dönemin sülfasalazin ile ilişkili olduğunu düşündürmüştür. Mental Bozuklukların Tanısal ve Sayımsal El Kitabı 5'e göre hasta "Maddenin/İlacin Yol Açtığ Depresyon Bozukluğu" tanısı ile takip edildi (7). Takip süresi boyunca aylık olarak kontrol edildi. Polikliniğimize teşhis konulduğu andan itibaren bir y1l geçti ve şu ana kadar hiçbir psikiyatrik belirti göstermedi.

Yapılan literatür taramasında günümüze kadar sülfasalazin ile psikiyatrik bozukluk gelişen üç olgu bildirilmiştir. Olguların ilkinde, ülseratif kolit nedeniyle sülfasalazin ile tedavi edilen hastada depresif bozukluğun; ikincisinde psöriatik artrit için düşük doz ve kısa süreli sulfasalazin ile psikoz kliniğinin geliştiği bildirilmiştir $(8,9)$. Sunulan son olguda, romatoid artrit nedeniyle klorokin kullanan hastaya sülfasalazin eklenmesinden sonra ciddi manik ve psikotik belirtiler tetiklenmiş, sonrasinda romatoloji konsultasyonu ile antiromatizmal ilaçları kesilmiş ve psikiyatrik tedavi başlandıktan 4 gün sonra belirtiler kaybolmuştur (10). Bizim olgumuzda da sülfasalazin kesilmesi sonrası 7 günde psikotik belirtiler tamamen kaybolmuştur.

Sülfasalazinin antiromatizmal etkilerinin ve muhtemel merkezi sinir sistem etkilerinin bilinmemesi sülfasalazin ile psikiyatrik bozukluk ilişkisi kurmamızı zorlaştırsa da, bildirilen olgu sunumları olgumuzda olduğu gibi sülfasalazinin duygudurum ve psikotik belirti spektrumunda yan etki yapabileceğini düşündürmektedir.

\section{Kaynaklar}

1. Onen F, Akar S, Birlik M, Sari I, Khan MA, Gurler $\mathrm{O}$ ve ark. Prevalence of ankylosing spondylitis and related spondyloarthritides in an urban area of Izmir, Turkey. J Rheumatol 2008;35 (2):305-309.

2. Chen J, Liu C. Sulfasalazine for ankylosing spondylitis. Cochrane Database Syst Rev 2005;18 (2):CD004800.

3. Joshi P, Dhaneshwar SS. An update on disease modifying antirheumatic drugs. Inflamm Allergy Drug Targets 2014;13(4):249-261.

4. Russinko PJ, Agarwal S, Choi MJ, Kelty PJ. Obstructive nephropathy secondary to sulfasalazine calculi. Urology 2003;62(4):748.

5. Simon LS. The treatment of rheumatoid arthritis. Best Pract Res Clin Rheumatol 2004;18:507-538.

6. Capell H, Madhok R. Disease-modifying antirheumatic drugs 2: sulfasalazine. Rheumatology, 4th ed. Philadelphia: Mosby Elsevier;2008. p. 437-47.

7. American Psychiatric Association, Desk reference to the Diagnostic Criteria for DSM-5, Arlington, APA, 2013.

8. Rebrov VG, Lukomskii MI. A case of depression in the treatment of nonspecific ulcerative 
colitis with sulfasalazine. Klin Med (Mosk) 1989;67 (8): 106.

9. Jajic Z, Jajic I. Acute psychoses in patients with psoriatic arthritis during treatment with sulfasalazine. Reumatizam 1998;46(1):43-4.

10. Gulec G, Yenilmez C, Ayranci U. Sulfasalazine plus chloroquine-induced mood disorder in a patient with rheumatoid arthritis. Iran J Med Sci 2009;34(1):72-75. 